\title{
Review of Chinese species of the leafhopper genus Scaphoidella Vilbaste, 1968 (Hemiptera, Cicadellidae, Deltocephalinae), with description of a new species
}

\author{
Jichun Xing', Zizhong Li' \\ I Institute of Entomology, Guizhou University; Guizhou Provincial Key Laboratory for Agricultural Pest Ma- \\ nagement of Mountainous Region; Special Key Laboratory for Development and Utilization of Insect Resources \\ of Guizhou, Guiyang, Guizhou,P.R. China, 550025
}

Corresponding author: Jichun Xing (xingjichun@126.com)

Academic editor: Mick Webb | Received 7 November 2014 | Accepted 12 March 2015 | Published 26 March 2015

http://zoobank.org/1AE29939-3E5A-4BC0-9D91-012181460286

Citation: Xing J, Li Z (2015) Review of Chinese species of the leafhopper genus Scaphoidella Vilbaste, 1968 (Hemiptera, Cicadellidae, Deltocephalinae), with description of a new species. ZooKeys 491: 79-93. doi: 10.3897/zookeys.491.8905

\begin{abstract}
The Chinese leafhopper species of the genus Scaphoidella Vilbaste are reviewed, and one new species Scaphoidella dietrichi sp. n. is described and illustrated. Two species are recorded from China for the first time: Scaphoidella clavatella Dai \& Dietrich, 2011 and Scaphoidella zhangi (Viraktamath \& Mohan, 2004). A key based on the male genitalia is given to distinguish Chinese species of this genus and a map provided their geographic distribution. The type specimens of the new species is deposited in the Institute of Entomology, Guizhou University, Guiyang, China (GUGC).
\end{abstract}

\section{Keywords}

Homoptera, morphology, taxonomy, distribution, China

Copyright Jichun Xing, Zizhong Li. This is an open access article distributed under the terms of the Creative Commons Attribution License (CC BY 4.0), which permits unrestricted use, distribution, and reproduction in any medium, provided the original author and source are credited. 


\section{Introduction}

The leafhopper genus Scaphoidella was established by Vilbaste (1968) for S. arboricola Vilbaste from the Maritime Territory of Russia. It belongs to the tribe Scaphoideini of subfamily Deltocephalinae (Zahniser \& Dietrich, 2013). Recently, Dai and Dietrich (2011) reviewed this genus and described ten new species from Thailand and Vietnam and at the same time, two new combinations Scaphoidella zhangi (Viraktamath \& Mohan, 2004), and S. punctulata (Melichar, 1903) were proposed (both previously placed in the genus Scaphoideus), the species S. datianensis Xing, Dai \& Li, 2008 was placed in the genus Monobazus, and S. transversa Li \& Xing, 2009 was excluded from Scaphoidella and treated as a species incertae sedis. The species $S$. denticlestyla Xing \& Li, 2010 (see Chen, Li and Jin 2010) and S. brevissima Dai, Xing \& Li (2011) in Scaphoidella (not listed in the checklist of Dai and Dietrich (2011)) are discussed below, bringing the total of known species to 20 , including eight from China.

In this paper, a new species: Scaphoidella dietrichi sp. n. is described and illustrated from Yunnan Province, China, and S. clavatella Dai \& Dietrich, 2011 and S. zhangi (Viraktamath \& Mohan, 2004) are recorded from China for the first time. The type specimens of the new species is deposited in the Institute of Entomology, Guizhou University, Guiyang, China (GUGC). The genus Scaphoidella now contains 21 species including 11 from China. A key is given to separate the Chinese species.

\section{Material and methods}

Terminology of morphological and genital characters follow Zhang and Dai (2006) and Dai and Dietrich (2011). Male specimens were used for the description and illustration. External morphology was observed under a stereoscopic microscope and characters were measured with an ocular micrometer. Color pictures for adult habitus were obtained by KEYENCE VHX-1000 system. The genital segments of the examined specimens were macerated in $10 \% \mathrm{NaOH}$ and drawn from preparations in glycerin jelly using a Leica MZ 12.5 stereomicroscope. Illustrations were scanned with Canon CanoScan LiDE 200 and imported into Adobe Photoshop 8 for labeling and plate composition.

\section{Taxonomy}

\section{Scaphoidella Vilbaste}

Scaphoidella Vilbaste, 1968: 133; Zhang and Dai 2006: 841; Li, Dai and Xing 2011: 199; Dai and Dietrich 2011: 458.

Type species. Scaphoidella arboricola Vilbaste, 1968.

For the relationship and diagnosis of Scaphoidella Vilbaste see Dai and Dietrich (2011: 458). 
Distribution. Oriental Region and Palaearctic Region (see Discussion).

\section{Checklist of species of Scaphoidella}

S. acaudata Zhang \& Dai, 2006 Distribution: China (Yunnan, Guizhou).

S. arboricola Vilbaste, 1968 Distribution: Russia (Maritime Territory); China (Zhejiang, Henan).

S.bifurcata Dai \& Dietrich, 2011 Distribution: Thailand (Chaiyaphum, Ubon Ratchathani, Phetchabun).

S. brevissima Dai, Xing \& Li, 2011 Distribution: China (Henan).

S. clavatella Dai \& Dietrich, 2011 Distribution: Thailand (Loei); China (Guangxi, Yunnan).

S. cornuta Dai \& Dietrich, 2011 Distribution: Thailand (Loei, Phetchabun).

S. coronoida Dai \& Dietrich, 2011 Distribution: Thailand (Chiang Mai, Loei).

S. denticlestyla Xing \& Li, 2010 Distribution: China (Guizhou).

S. dietrichi Xing \& Li, sp. n. Distribution: China (Yunnan).

S. digitatus Dai \& Dietrich, 2011 Distribution: Thailand (Ubon Ratchathani, Khonkaen).

S. dimidiatus Dai \& Dietrich, 2011 Distribution: Thailand (Chaiyaphum, Loei, Phetchabun).

S. dongnaiensis Dai \& Dietrich, 2011 Distribution: Vietnam (Dongnai).

S. flangenella Dai \& Dietrich, 2011 Distribution: Thailand (Ubon Ratchathani).

S. lamella Dai \& Dietrich, 2011 Distribution: Thailand (Loei, Phetchabun, Phitsanulok, Sakon Nakhon, Ubon Ratchathani).

S. punctulata (Melichar, 1903) Distribution: Sri Lanka.

S. stenopaea Anufriev, 1977 Distribution: Russia (Amur Province, Maritime Territory);

China (Shaanxi, Shandong, Heilongjiang, Liaoning, Gansu, Inner Mongolia, Hebei, Shanxi).

S. undosa Zhang \& Dai, 2006 Distribution: China (Henan, Hunan, Jiangxi, Hubei, Guizhou, Zhejiang, Anhui).

S. unihamata (Li \& Kuoh, 1993) Distribution: China (Zhejiang, Hunan, Fujian, Guangxi).

S. viraktamathi Dai \& Dietrich, 2011 Distribution: Thailand (Phetchabun, Sakon Nakhon).

S. wideaedeaga (Wang \& Li, 2004) Distribution: China (Yunnan, Xizang); Thailand (Loei).

S. zhangi (Viraktamath \& Mohan, 2004) Distribution: India (Meghalaya, West Bengal);

Thailand (Loei); China (Guizhou).

\section{Key to species (males) of Scaphoidella from China}

$1 \quad$ Pygefer side with conspicuous spine on dorsal margin (Figs 19, 37)...........2

- $\quad$ Pygefer side without spine on dorsal margin ................................................ 3

2 Pygofer side with caudal margin round, without spine (Fig. 19) .... S. clavatella 
- $\quad$ Pygofer side with ventrally directed spine on caudal margin (Fig. 37)...S. zhangi 3 Subgenital plate with lateral macrosetae arranged irregularly (Zhang and Dai

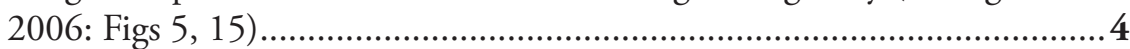

- Subgenital plate with lateral macrosetae in single row ................................5

4 ygofer process long; subgenital plate tapered apically; basal processes of aedeagus extending to near apex of shaft (Zhang and Dai 2006: Figs 4-6) ....... S. undosa

- $\quad$ Pygofer process short; subgenital plate rounded apically; basal processes of aedeagus extending beyond shaft (Zhang and Dai 2006: Figs 14-16).....S. arboricola

5 Pygofer side with caudal process (Fig. 13; Zhang and Dai 2006: Figs 33, 44) ... 6

- $\quad$ Pygofer side without caudal process ..........................................................8

6 Apex of aedeagal shaft with pair of lateral processes; preatrium short (Zhang and Dai 2006: Figs 28, 29) ..................................................... S. stenopaea

- $\quad$ Apex of aedeagal shaft without processes; preatrium very long (Fig. 17; Zhang

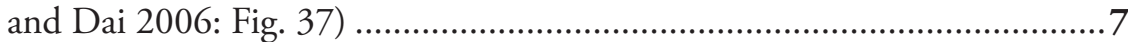

$7 \quad$ Style apical process moderately long (Fig. 18) ............................ b. brevissima

- $\quad$ Style apical process very long (Zhang and Dai 2006: Fig. 39) ..S.unihamata

8 Apical margin of aedeagal shaft with many small spines on both sides (Figs $34,35)$

S. dietrichi sp. n.

- $\quad$ Aedeagal shaft without small spinose processes ............................................9

9 Aedeagal shaft in lateral view distinctly broadened near midlength; stem of connective nearly $1 / 3$ length of arms (Zhang and Dai 2006: Figs 47, 50) .....

S. wideaedeaga

- $\quad$ Aedeagal shaft in lateral view slender and not broadened near midlength; stem of connective and arms of approximately equal length (Figs 28, 29; Zhang and Dai 2006: Figs 57,58).

10 Preatrium of aedeagus very long; style apical process with teeth (Figs 29, 30) ... S. denticlestyla

- $\quad$ Preatrium of aedeagus short; style apical process without teeth (Zhang and Dai 2006: Figs 55, 57)

S. acaudata

\section{Chinese Scaphoidella species}

\section{Scaphoidella acaudata Zhang \& Dai, 2006}

Scaphoidella acaudata Zhang \& Dai, 2006: 850, figs 51-58; Li, Dai and Xing 2011: 199, plate 5-194, figs 1-6.

Material examined. 1 $\widehat{\text {, }}$, China: Guizhou Prov., Bailidujuan, 18 October 2007, coll. Yujian Li (GUGC); 10̂, Yunnan Prov., Longling, Longxin, 10 June 2011, coll. Jiankun Long (GUGC).

Distribution. China (Yunnan, Guizhou) (Fig. 43). 


\section{Scaphoidella arboricola Vilbaste, 1968}

Scaphoidella arboricola Vilbaste, 1968: 133, plate 110, figs 1-8; Zhang and Dai 2006: 850 , figs $1-10$.

Distribution. Russia (Maritime Territory); China (Zhejiang, Henan) (Fig. 43).

\section{Scaphoidella brevissima Dai, Xing \& Li, 2011}

Figs 1-2, 13-18

Scaphoidella brevissima Dai, Xing \& Li, 2011: 1, figs 1-10.

Material examined. China: $1 \widehat{\jmath}$ (Holotype), Henan Prov., Luanchuan County, Heyu, 19 August 2008, coll. Jichun Xing (GUGC); 1 , Henan Prov., Xixia County, Taiping, 30 July 2010, coll. Hu Li and Zhihua Fang (GUGC).

Distribution. China (Henan) (Fig. 43).

Note. This species was described from China (Henan) based on the male holotype (GUGC).

\section{Scaphoidella clavatella Dai \& Dietrich, 2011}

Figs 3-4, 19-24

Scaphoidella clavatella Dai \& Dietrich, 2011: 468. figs 51-55.

Material examined. $1 \hat{\jmath}$, China: Guangxi Autonomous Region, Daxin County, Detianpubu, 11 May 2012, coll. Zhihua Fan (GUGC); $1 \overbrace{}^{\Uparrow} 1$, Yunnan Prov., Menghai, 13 July 2013, coll. Jichun Xing (GUGC).

Distribution. Thailand (Loei); China (Guangxi, Yunnan) (Fig. 43).

Note. This species was described from Thailand (Loei) based on two male specimens (QSBG and INHS). This species is here recorded from China for the first time.

\section{Scaphoidella denticlestyla Xing \& Li, 2010}

Figs 5-6, 25-30

Scaphoidella denticlestyla Xing \& Li (in Chen et al.), 2010: 138, Figs 7-14; Li, Dai and Xing 2011: 200, plate 5-195, figs 1-8.

Material examined. China: $1{ }^{\Uparrow}$ (Holotype), Guizhou Prov., Mayanghe, Maojia, 5

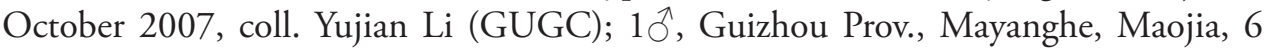
October 2007, coll. Qiongzhang Song (GUGC). 

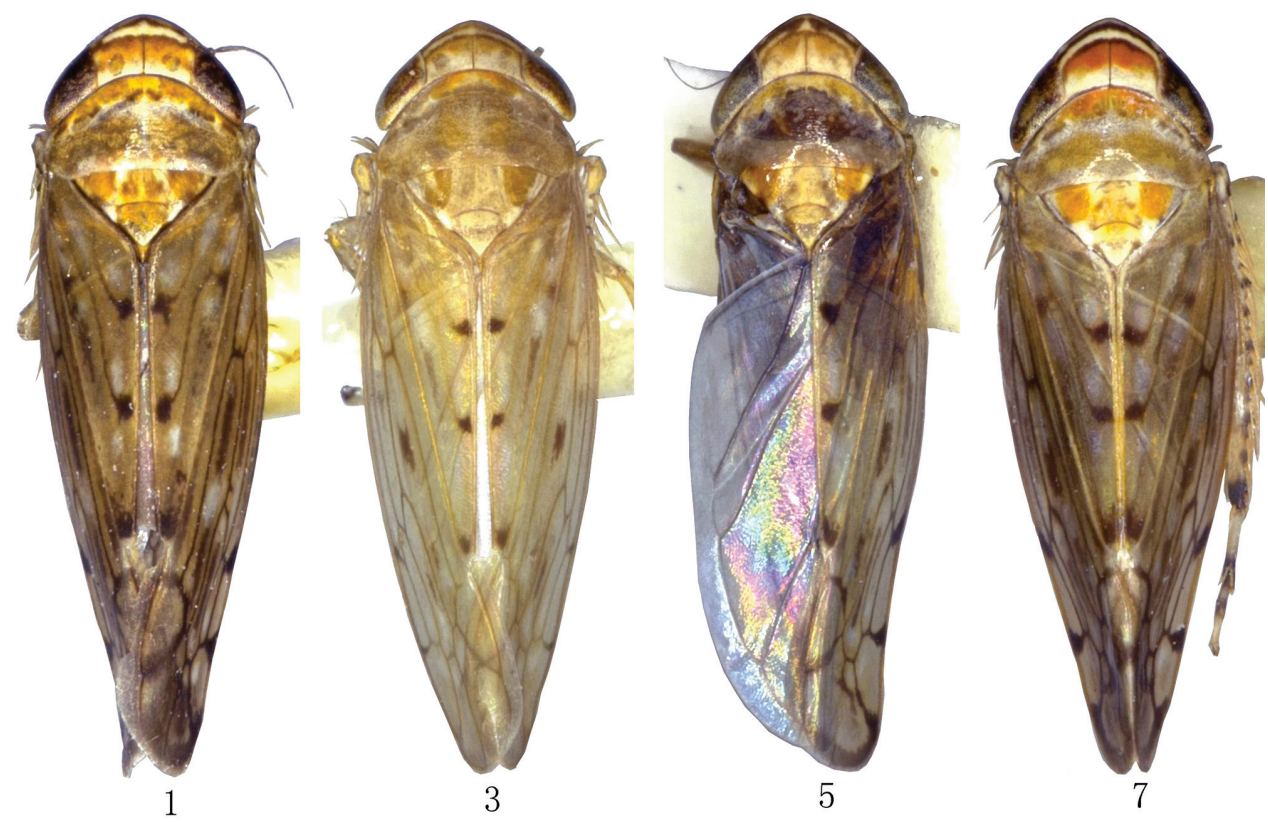

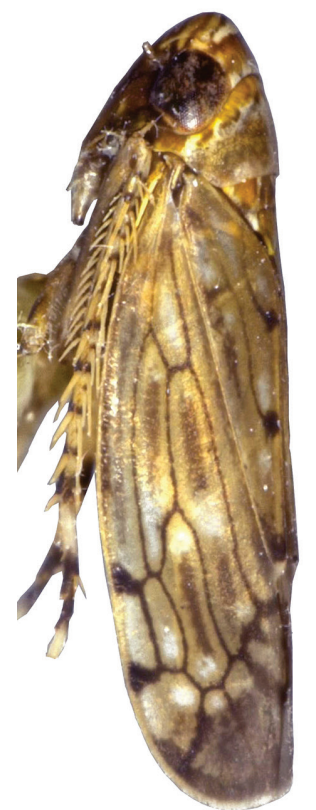

2

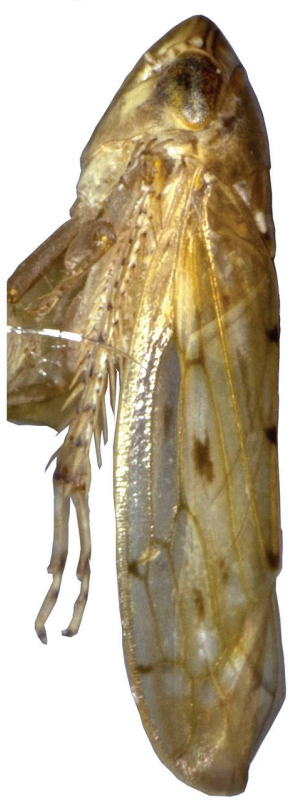

4

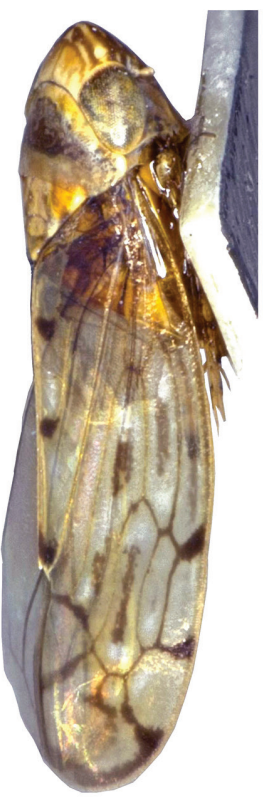

6

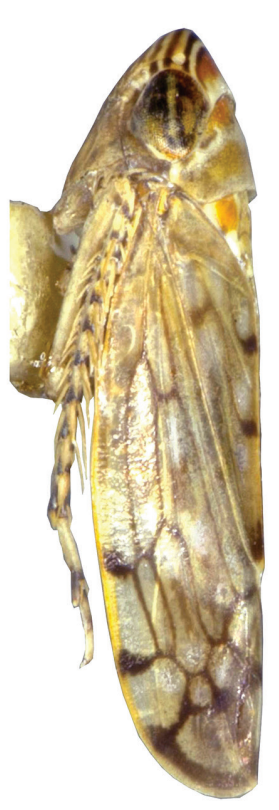

8

Figures I-8. Scaphoidella species. I, 2 Scaphoidella brevissima Dai, Xing \& Li I $\hat{~}$, dorsal view $2 \hat{\text { ô }}$,

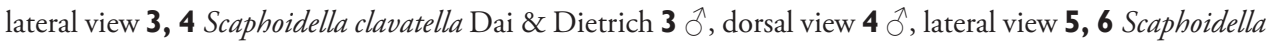

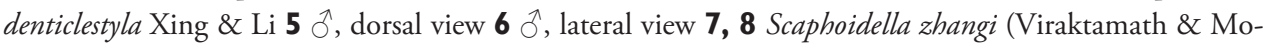

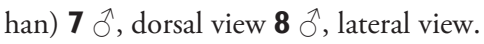


Distribution. China (Guizhou) (Fig. 43).

Note. This species was described from China (Guizhou) based on two male specimens deposited in GUGC. As the original figures of Xing \& Li (in Chen et al. 2010 and Li et al. 2011) are not very perfect the male genitalia are redrawn here by the first author.

Scaphoidella dietrichi Xing \& Li, sp. n.

http://zoobank.org/414D9E83-6DF9-4F74-BECC-55886B131911

Figs 9-12, 31-36

Description. Body ochraceous. Head with piceous submargial band on anterior margin, one transverse arcuate band between eyes anteriorly, narrowly margined with piceous, orange red (Figs 9, 11). Face with thin, arcuate, piceous submarginal band (Fig. 12). Pronotum with anterior brown and posterior submarginal chocolate brown transverse bands (Fig. 11). Forewing ochraceous, with hyaline spots (Figs 9, 10).

Vertex shorter than pronotum, shorter medially than next to eye. Pronotum longer than scutellum (Fig. 11). External features as in generic description (see Dai and Dietrich 2011: 458).

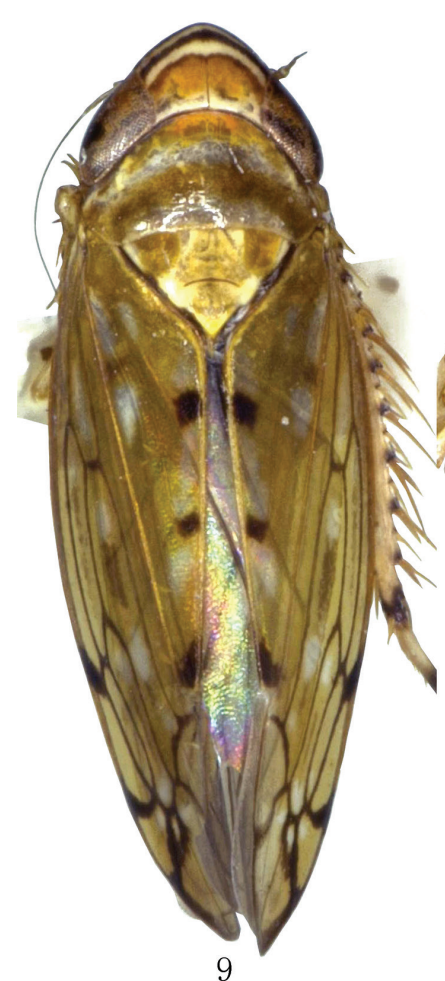

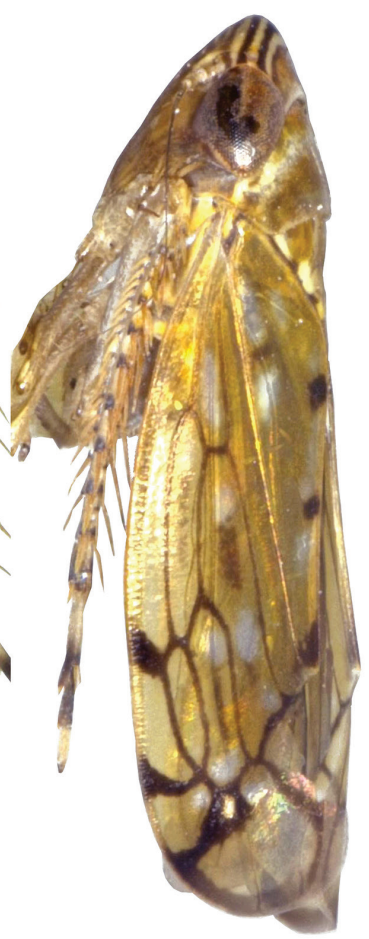

10
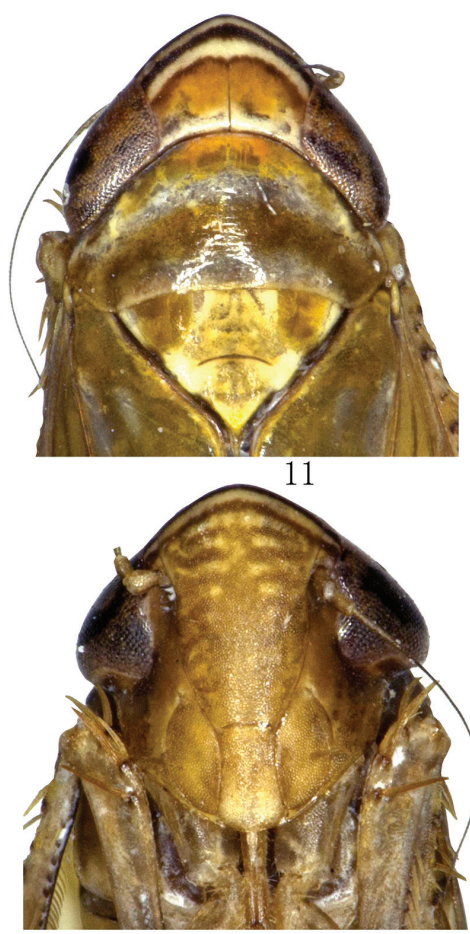

12

Figures 9-I 2. Scaphoidella dietrichi sp. n., Ô. 9 dorsal view I 0 lateral view I I head and thorax, dorsal view $\mathbf{I} 2$ face. 

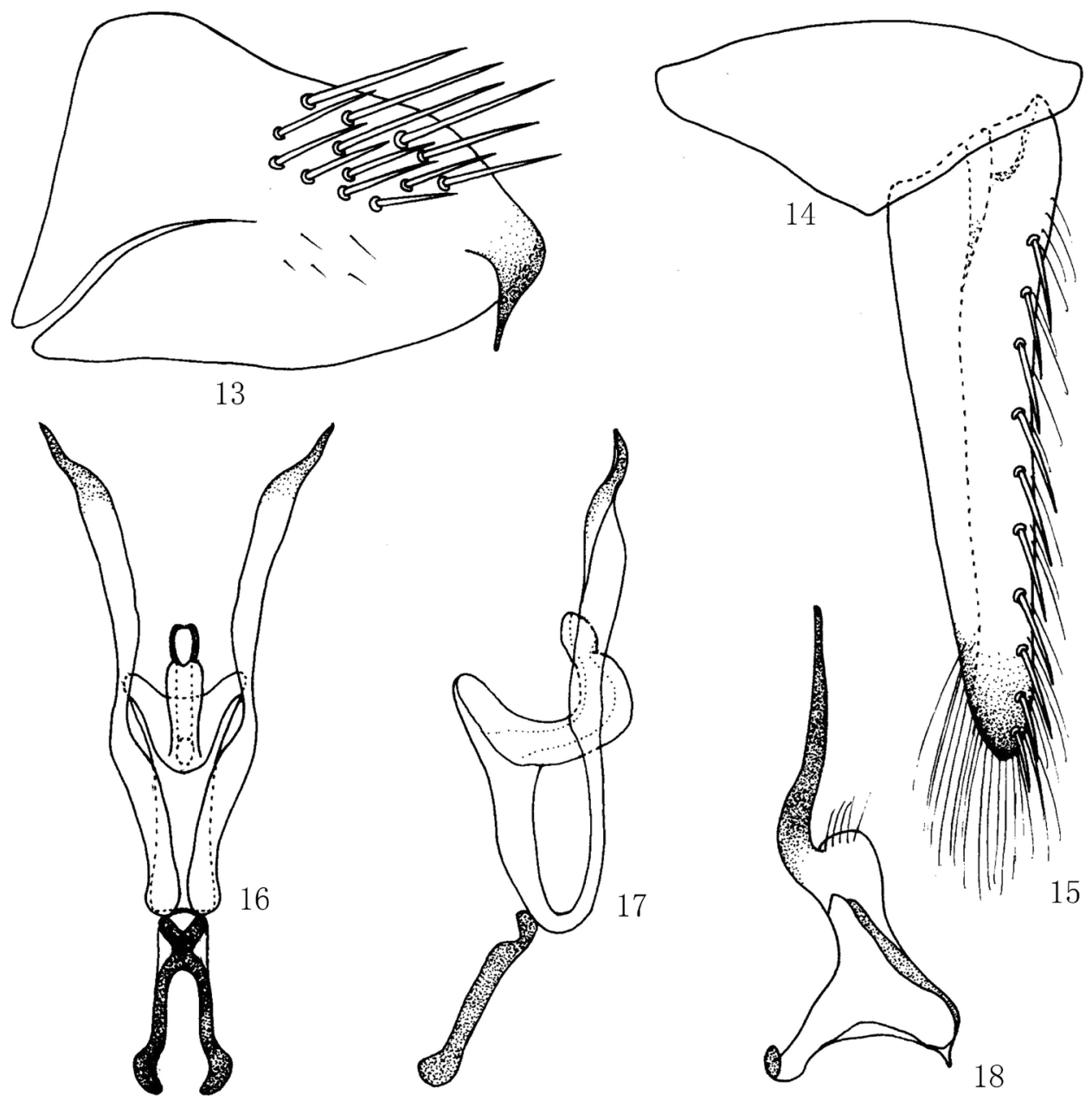

15

Figures 13-18. Scaphoidella brevissima Dai, Xing \& Li, I3 Male pygofer side, lateral view I4 Valve, ventral view $\mathbf{1 5}$ Subgenital plates, ventral view $\mathbf{1 6}$ Aedeagus and connective, ventral view 17 Aedeagus and connective, lateral view 18 Style, dorsal view.

Male genitalia. Pygofer in lateral aspect tapering posteriorly from midlength, with many short and long macrosetae dorsally, without caudal process (Fig. 31). Valve large, subtriangular (Fig. 32). Subgenital plate elongate, narrowing to rounded apex, uniseriate row of macrosetae along ventrolateral margin and additional hair-like setae at apex (Fig. 33). Aedeagal shaft curved dorsally, its apical margin with many small spines on both sides, gonopore apical, preatrium very long; basal processes slender, tapering apically, extended to near apex of aedeagal shaft (Figs 34, 35). Connective Y-shaped, articulated with aedeagus, its stem nearly $1 / 3$ length of arms (Fig. 34). Style elongate, with prominent subapical lobe, apophysis slender and narrowed distally, equal to $1 / 2$ length of style (Fig. 36). 


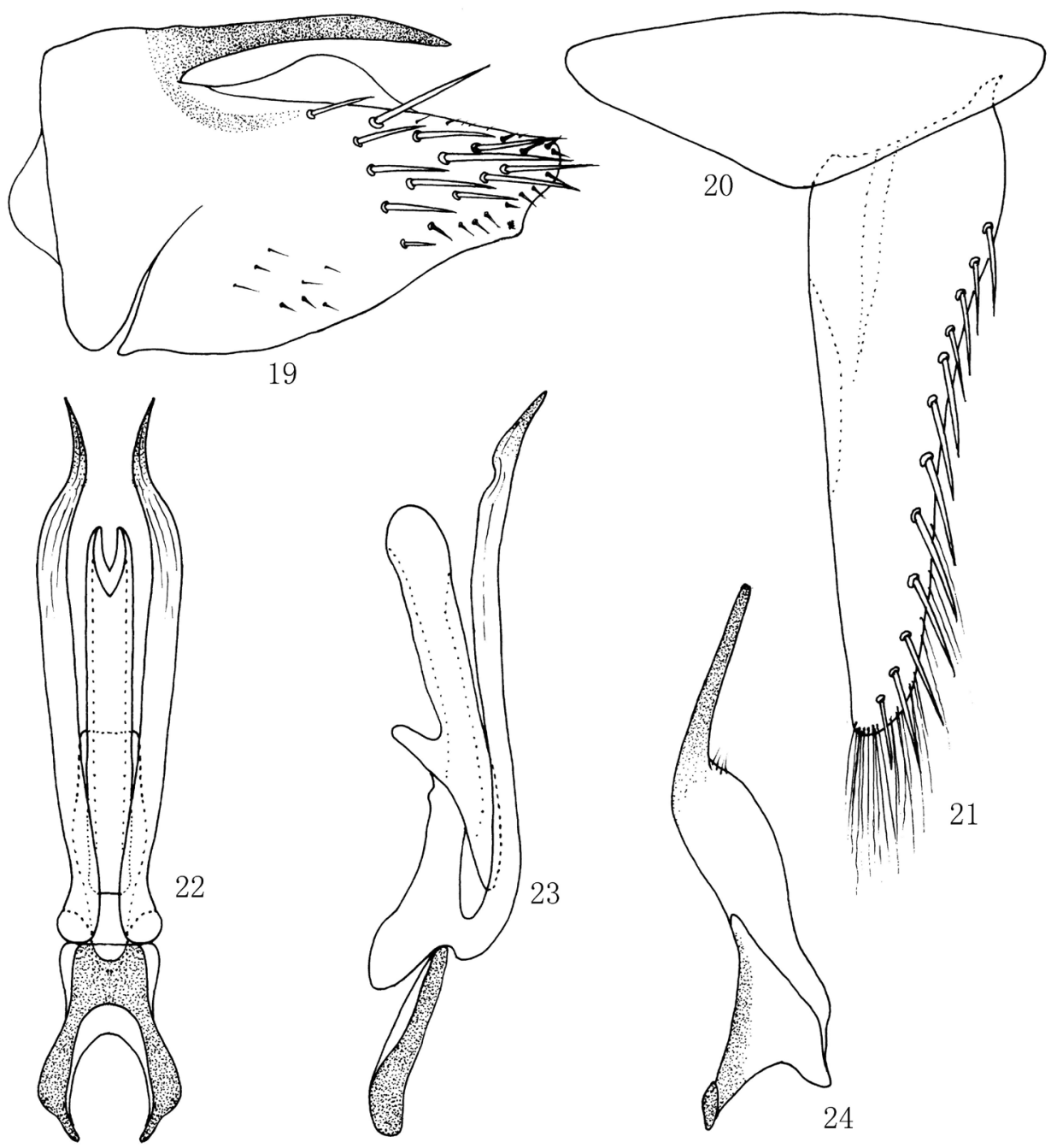

Figures 19-24. Scaphoidella clavatella Dai \& Dietrich, 19 Male pygofer side, lateral view 20 Valve, ventral view 2 I Subgenital plates, ventral view 22 Aedeagus and connective, ventral view 23 Aedeagus and connective, lateral view $\mathbf{2 4}$ Style, dorsal view.

Measurement. Length (including tegmen): $\widehat{\partial}, 4.4 \mathrm{~mm}$.

Type material. Holotype $\hat{\jmath}$, China: Yunnan Prov., Xishuangbanna, Menglun, 28 July 2012, coll. Weibin Zheng (GUGC).

Host. Grasses.

Distribution. China (Yunnan) (Fig. 43).

Diagnosis. This species is similar to Scaphoidella zhangi (Viraktamath \& Mohan, 2004), but can be distinguished from the latter by the male pygofer without caudal process and spine on dorsal margin, apical margin of aedeagal shaft with many small spinose processes on both sides, and aedeagal shaft curved dorsally. 


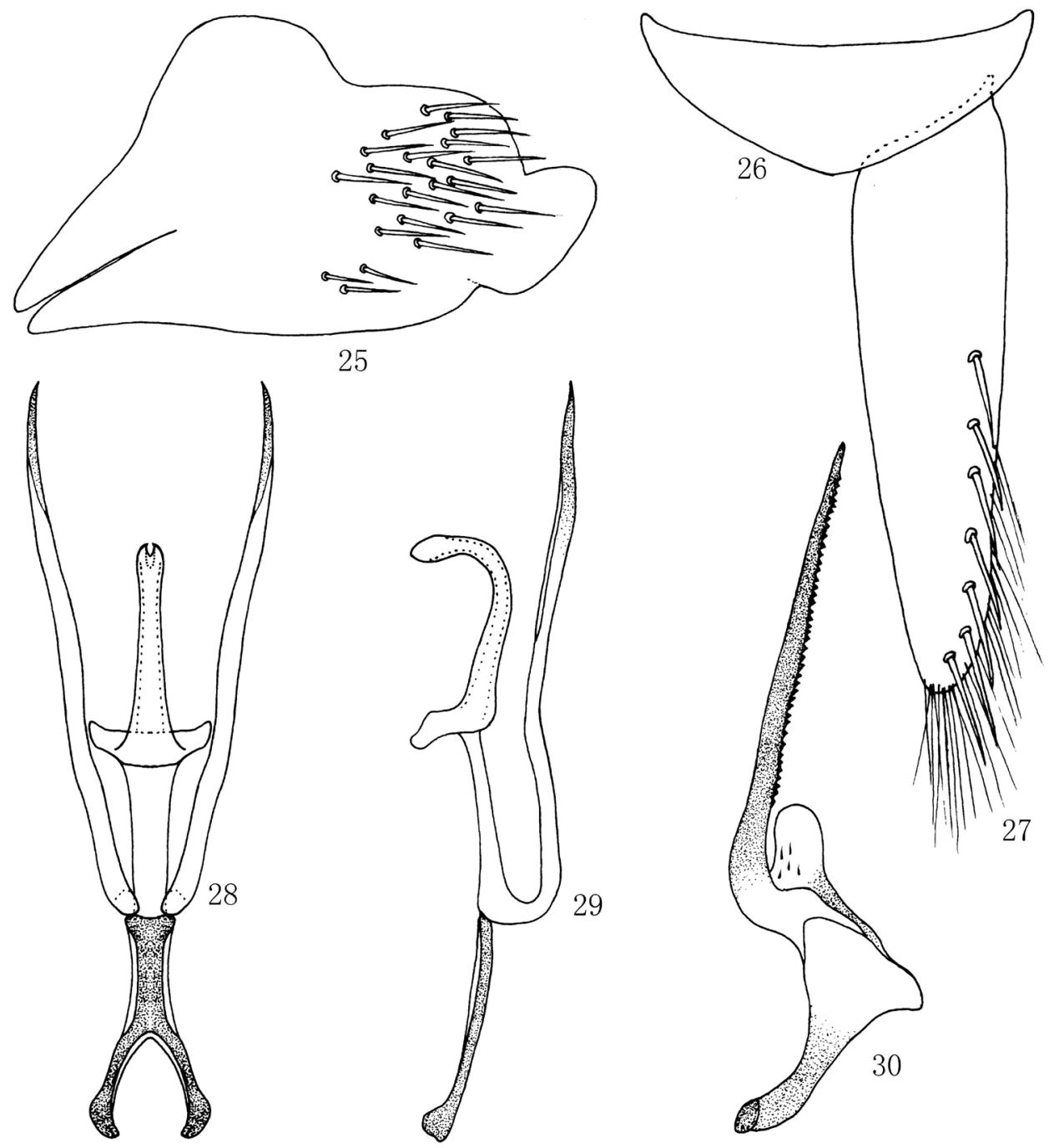

Figures 25-30. Scaphoidella denticlestyla Xing \& Li, 25 Male pygofer side, lateral view 26 Valve, ventral view 27 Subgenital plates, ventral view 28 Aedeagus and connective, ventral view 29 Aedeagus and connective, lateral view $\mathbf{3 0}$ Style, dorsal view.

Etymology. This new species is named after Dr. C. H. Dietrich (INHS) in recognition of his good work on leafhoppers.

\section{Scaphoidella stenopaea Anufriev, 1977}

Scaphoidella stenopaea Anufriev, 1977: 213, figs 13-19; Zhang and Dai 2006: 847, figs 23-29; Li, Dai and Xing 2011: 201, plate 5-196, figs 1-6. 

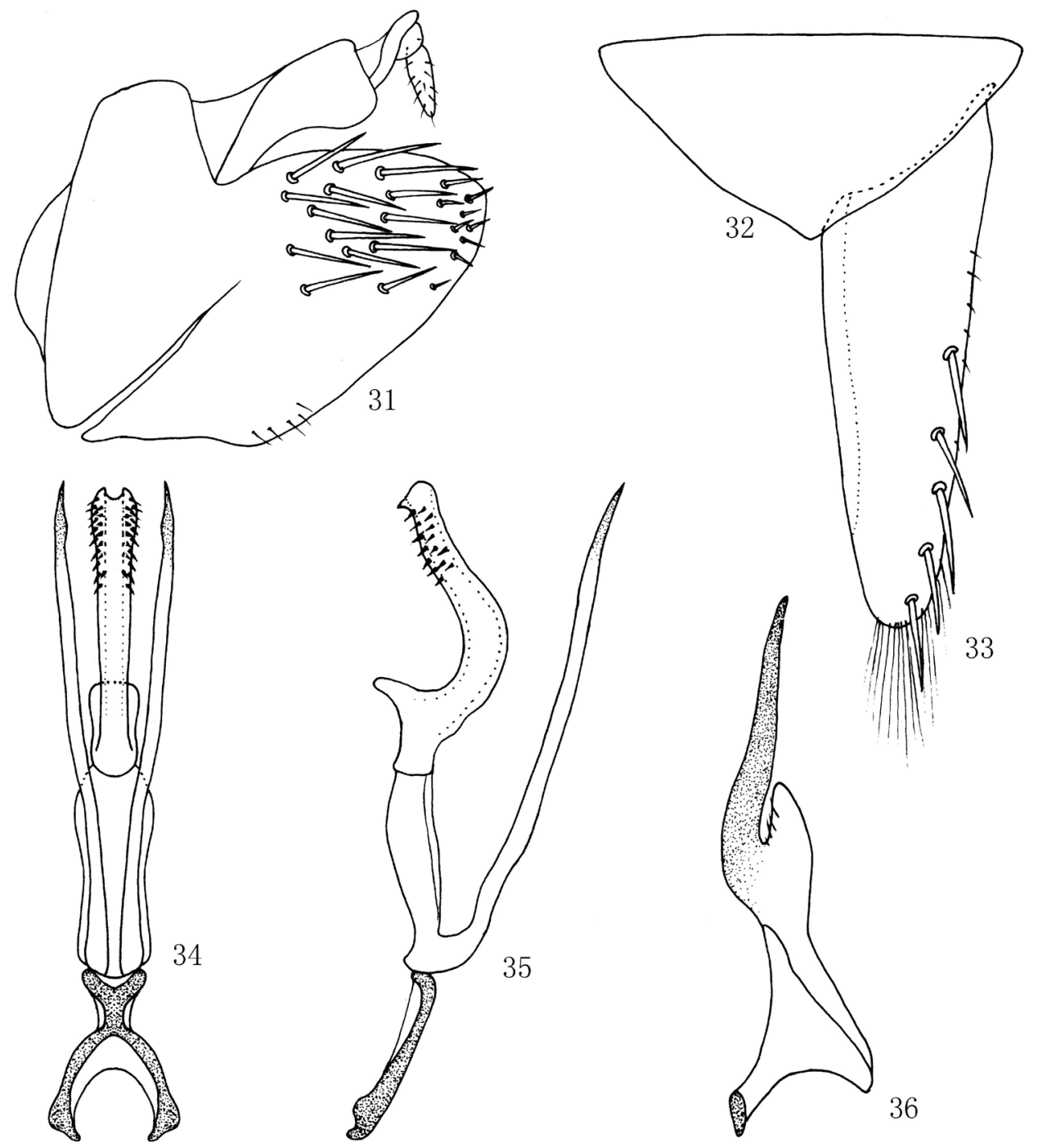

Figures 3 I-36. Scaphoidella dietrichi sp. n., 3 I Male pygofer side, lateral view 32 Valve, ventral view 33 Subgenital plates, ventral view $\mathbf{3 4}$ Aedeagus and connective, ventral view $\mathbf{3 5}$ Aedeagus and connective, lateral view 36 Style, dorsal view.

Material examined. $3 \hat{\jmath} 4 ㅇ ㅜ$, China: Inner Mongolia Autonomous Region, Zhalan-

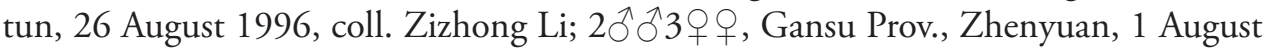

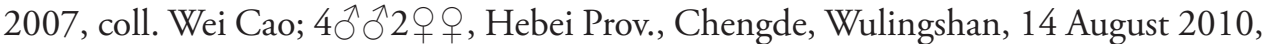
coll. Lixia Xie; $2 \widehat{\jmath}$, Shanxi Prov., Lishan, Dahelinchang, 23 July 2012, coll. Jichun Xing. All GUGC.

Distribution. Russia (Amur Province, Maritime Territory); China (Shaanxi, Shandong, Heilongjiang, Liaoning, Gansu, Inner Mongolia, Hebei, Shanxi) (Fig. 43). 


\section{Scaphoidella undosa Zhang \& Dai, 2006}

Scaphoidella undosa Zhang \& Dai, 2006: 844, figs 11-22; Li, Dai and Xing 2011: 204, plate 5-199, figs 1-7.

Material examined. $1 \delta^{\Uparrow} 2 q+$, China: Guizhou Prov., Kuankuoshui, 24 August 2001, coll. Zizhong Li; $1 \hat{\jmath}$, Guizhou Prov., Congjiang County, Yueliangshan, 20 July

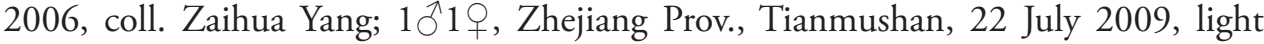
trap coll. Zehong Meng; $1 \widehat{\text { }}$, Guizhou Prov., Kuankuoshui, 11 August 2010, coll. Hu

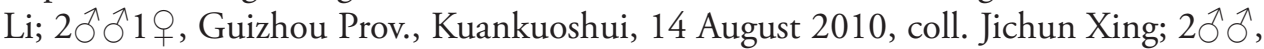
Guizhou Prov., Kuankuoshui, 17 August 2010, coll. Hu Li and Zhihua Fan; $2 \hat{\jmath} \widehat{\partial}$, Anhui Prov., Jinzhai County, Tianma, 31 July 2013, coll. Bin Li. All GUGC.

Distribution. China (Henan, Hunan, Jiangxi, Hubei, Guizhou, Zhejiang, Anhui) (Fig. 43).

\section{Scaphoidella unihamata (Li \& Kuoh, 1993)}

Scaphoideus unihamatus Li \& Kuoh, 1993: 39, figs 7-12.

Scaphoidella inermis Cai \& He, 2001: 205, figs 89-96, synonymised by Zhang and Dai 2006: 848.

Scaphoidella unihamata (Li \& Kuoh), comb. n. by Zhang and Dai 2006: 848, figs 30-40; Li, Dai and Xing 2011: 203, plate 5-198, figs 1-5.

Material examined. China: $1 \widehat{\circlearrowleft}$ (Holotype), Fujian Prov., Sanming, 6 September 1978, coll. Zhonglin Ge; $2 \widehat{\jmath} \widehat{\jmath}$, Fujian Prov., Sanming, 6 September 1978, coll. Zhonglin Ge; $1 \hat{\jmath}$, Guangxi Autonomous Region, Huaping, 19 May 2012, coll. Zhihua Fan. All GUGC.

Distribution. China (Zhejiang, Hunan, Fujian, Guangxi) (Fig. 43).

\section{Scaphoidella wideaedeaga (Wang \& Li, 2004)}

Scaphoideus wideaedeagus Wang \& Li, 2004: 17, figs 14-19.

Scaphoidella wideaedeaga (Wang \& Li), comb. n. by Zhang and Dai 2006: 849, figs 41-50;

Li, Dai and Xing 2011: 205, plate 5-200, figs 1-6; Dai and Dietrich 2011: 472.

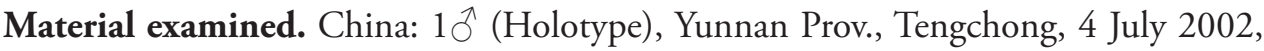

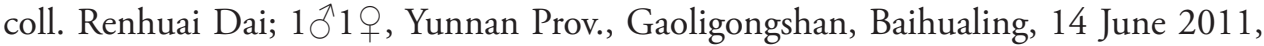

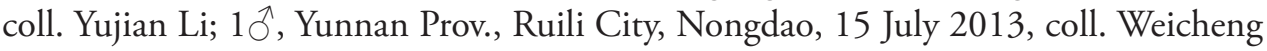
Yang; 1ð̂, Yunnan Prov., Gaoligongshan, Baihualing, 5 August 2013, coll. Zhihua Fan. All GUGC.

Distribution. China (Yunnan, Xizang) (Fig. 43), Thailand (Loei). 


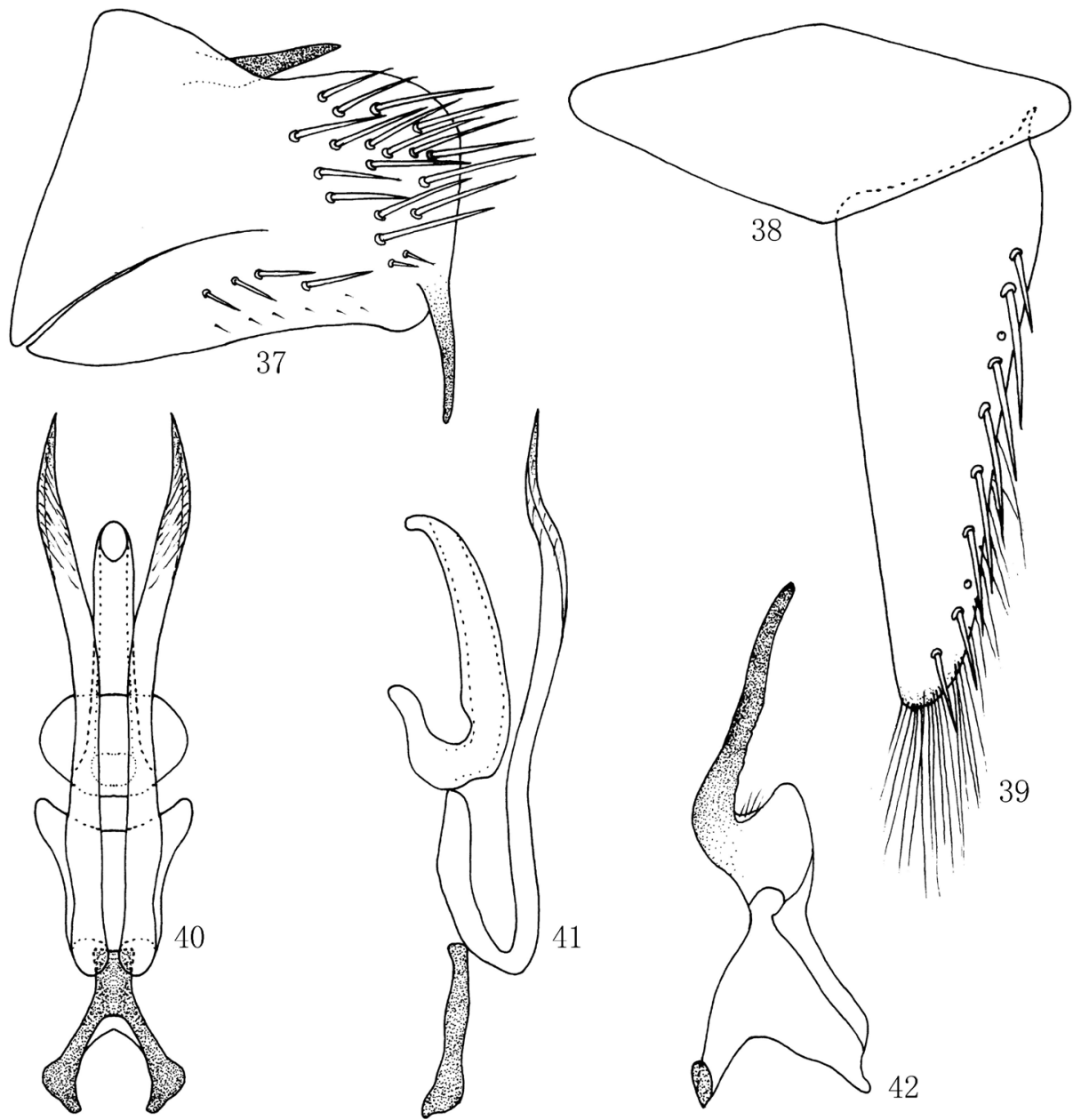

Figures 37-42. Scaphoidella zhangi (Viraktamath \& Mohan), 37 Male pygofer side, lateral view 38 Valve, ventral view 39 Subgenital plates, ventral view $\mathbf{4 0}$ Aedeagus and connective, ventral view 41 Aedeagus and connective, lateral view 42 Style, dorsal view.

\section{Scaphoidella zhangi (Viraktamath \& Mohan, 2004)}

Figs 7-8, 37-42

Scaphoideus zhangi Viraktamath \& Mohan, 2004: 45, figs 218-227.

Scaphoidella zhangi comb. n. by Dai and Dietrich 2011: 471.

Material examined. 1ðึ, China: Guizhou Prov., Luodian County, Bamao, 20 October 2002, coll. Renhuai Dai (GUGC).

Distribution. India (Meghalaya, West Bengal); Thailand (Loei); China (Guizhou) (Fig. 43).

Note. This species is here recorded from China for the first time. 


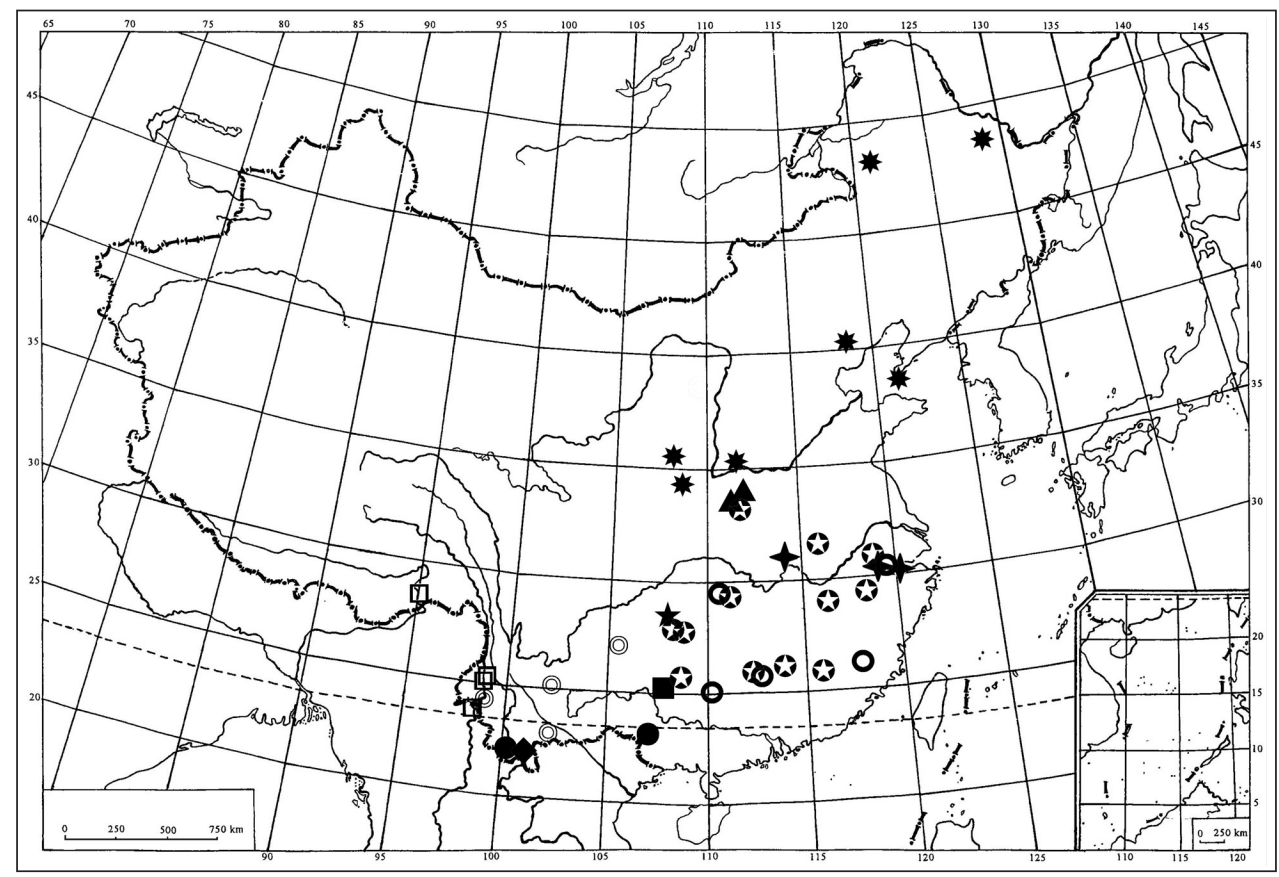

Figure 43. Geographic distribution of Scaphoidella species in China: S. acaudata (@); S. arboricola (†);

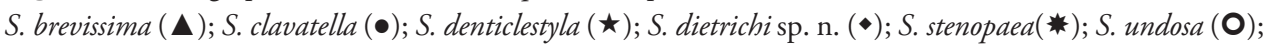
S. unihamata $(\mathbf{*})$; S. wideaedeaga $(\mathbf{\square})$; S. zhangi $(\mathbf{\square})$.

\section{Discussion}

Chinese species of Scaphoidella are mainly distributed in southern China (S. acaudata, S. clavatella, S. denticlestyla, S. dietrichi, S. unihamata, and S. zhangi) with S. brevissima and S. stenopaea distributed in the Palaearctic Region (northern China and also Inner Mongolia). The following Chinese species occur in both regions: S. arboricola, S. undosa, and S. wideaedeaga. Until now, six species: S. acaudata, S. brevissima, S. denticlestyla, S. dietrichi, S. undosa, and S. unihamata are endemic to China and S. stenopaea, $S$. undosa, and $S$. unihamata appear to be widespread. It is highly likely that there are undiscovered species in China.

\section{Acknowledgements}

We are grateful to collectors for collecting specimens, and also thank Mr. M. D. Webb $(\mathrm{BMNH})$ and two other reviewers for reading the manuscript and making some suggestions. This work was supported by the Science and Technology Foundation of Guizhou Province (J-[2014]2063), National Natural Science Foundation of China (31301909) and China Postdoctoral Science Foundation funded project (2013T60864, 2012M521719), all awarded to the first author. 


\section{References}

Anufriev GA (1977) Two new species of Auchenorrhynchous Insects from the Temperate Asia (Homoptera). Reichenbachia 16(21): 211-215.

Cai P, He JH, Gu XL (2001) Homoptera: Cicadellidae. In: Wu H, Pan CW (Eds) Insects of Tianmushan National Nature Reserve. Science Press, Beijing, China, 132-145. [In Chinese with English summary]

Dai RH, Xing JC, Li H (2011) One new species of the genus Scaphoidella from China (Hemiptera, Cicadellidae, Deltocephalinae). Journal of Guizhou Normal University (Natural Sciences) 29(3): 1-2. [In Chinese with English summary]

Dai W, Dietrich CH (2011) Review of the Old World leafhopper genus Scaphoidella Vilbaste (Hemiptera: Cicadellidae: Deltocephalinae), with description of ten new species from Thailand and Vietnam. Annales de la Société entomologique de France (N.S.) 47(3-4): 457-473. doi: 10.1080/00379271.2011.10697737

Li ZZ, Dai RH, Xing JC (2011) Deltocephalinae from China (Hemiptera: Cicadellidae). Popular Science Press, Beijing, China, 336 pp. [In Chinese with English summary]

Li ZZ, Kuoh CL (1993) Two new species of the genus Scaphoideus from Fujian China (Homoptera: Euscelidae). Journal of Guizhou Agricultural College 12(1): 37-40. [In Chinese with English summary]

Li ZZ, Xing JC (2009) A new species of the genus Scaphoidella Vilbaste (Hemiptera: Cicadellidae: Euscelinae) from China. Entomotaxonomia 31(2): 99-101. [In Chinese with English summary]

Vilbaste J (1968) Systematic treatise of cicadas found on the edge of the coastal regions. Uber die Zikadenfauna des Primorje Gebietes. Valgus, Tallin, 195 pp.

Viraktamath CA, Mohan GS (2004) A revision of the deltocephalinae leafhopper genus Scaphoideus (Hemiptera: Cicadellidae) from the Indian subcontinent. Zootaxa 578: 1-48.

Wang LM, Li ZZ (2004) Three new species of the genus Scaphoideus (Homoptera: Cicadellidae: Euscelinae) from Yunnan. Entomotaxonomia 26(1): 15-18. [In Chinese with English summary]

Xing JC, Dai RH, Li ZZ (2008) A new species of genus Scaphoidella from Hainan Province in China (Hemiptera: Cicadellidae: Euscelinae). Sichuan Journal of Zoology 27(6): 963-965. [In Chinese with English summary]

Xing JC, Li ZZ (2010) Hemiptera: Cicadellidae: Eusceline. In: Chen XS, Li ZZ, Jin DC (Eds) Insects From Mayanghe Landscape. Guizhou Science and Technology Publishing House, Guiyang, China, 132-145. [In Chinese with English summary]

Zahniser JN, Dietrich CH (2013) A review of the tribes of Deltocephalinae (Hemiptera: Auchenorrhyncha: Cicadellidae). European Journal of Taxonomy 45: 1-211. doi: 10.5852/ ejt.2013.45

Zhang YL, Dai W (2006) A taxonomic study on the leafhopper genus Scaphoidella Vilbaste (Hemiptera: Cicadellidae: Deltocephalinae) from China. Zoological Science 23(10): 843-851. 